\section{Methicillin-Resistant Staphylococcus aureus, Public Concern, and Legislative Mandates}

To the Editor-The recent position statement from the Society for Healthcare Epidemiology of America (SHEA) and the Association for Professionals in Infection Control and Epidemiology (APIC) regarding current trends towards regulated mandates for control of methicillin-resistant Staphylococcus aureus (MRSA) is well thought and articulated. ${ }^{1}$ The call to develop more encompassing and comprehensive approaches for MRSA control is a critical conclusion. Whereas the legislation and its technical consequences may at first draw the most attention, it is the main thrust of such action that may be lost in the plethora of discussions that arise.

That MRSA is a major nosocomial pathogen in North America is not new. ${ }^{2}$ The epidemic and consequences of community-acquired MRSA have more recently drawn increased attention from a lay perspective. It is becoming apparent that the increasing burden of MRSA infection, whether hospitalacquired or community-acquired, is being associated with rising mortality due to MRSA infection. ${ }^{3}$ Proportionately, the costs of infection and its containment continue to escalate. ${ }^{4}$ Whereas the public is less likely to recognize an infection that predominantly occurs in institutions, it is more likely to respond when seemingly healthy individuals succumb to serious and dramatic consequences of infection: a central nervous system MRSA infection after clean neurosurgery, death of a newborn because of MRSA sepsis, or a series of major boils and cellulitides among healthy athletes, are a few examples.

The legislated attempts to enhance MRSA control by elected officials reflects both a sense of urgency and a sense of futility regarding the existing circumstances. They are a call to action for a problem that has long been festering, despite decades of knowledge and scientific publication. Does the public not have a right to activate duly elected representatives to improve the human condition? If infection control staff and public health officials were selected by democratic election, would the public choose the status quo, given their perception of MRSA infection?

Use of public policy to control infection is not new. The obligation to notify public health authorities about certain diseases, public health interventions regarding sexually transmitted diseases, historic routine screening at hospital admission for syphilis, and routine screening for various infections during pregnancy are but a few such time-honored interventions. In the United Kingdom, the control of MRSA has attracted considerable political attention, to the point that it has entered national health policy and debate within legislative assemblies. ${ }^{5}$

Even if proposed state legislation never comes to be adopted or enforced, the message from the public, through its elected officials, is clear. The public aspires to better control of MRSA and improved outcomes. It wishes that the currently fractionated approaches would become cohesive so that a major gain in public safety is realized. It is sending a message to unelected medical staff and administrators and to unelected public health officials for them to move beyond current levels of activism. As a potential benefit to health care personnel, a public call to control MRSA may also be viewed as a public acknowledgement that use of additional resources may be acceptable to achieve that goal. The true societal impact of MRSA infection may go beyond the eye of public perception but not beyond the public's sense that change is long overdue.

\section{ACKNOWLEDGMENTS}

Potential conflicts of interest. The author reports no conflicts of interest relevant to this report.

\section{Nevio Cimolai, MD, FRCP(C)}

Department of Pathology and Laboratory Medicine, Children's and Women's Health Centre of British Columbia, Vancouver, British Columbia, Canada

Address reprint requests to: Nevio Cimolai, Department of Pathology and Laboratory Medicine, Children's and Women's Health Centre of British Columbia, 4480 Oak Street, Vancouver, BC, V6H3V4, Canada (ncimolai@ interchange.ubc.ca).

Infect Control Hosp Epidemiol 2007; 28:896-896

(C) 2007 by The Society for Healthcare Epidemiology of America. All rights reserved. 0899-823X/2007/2807-0024\$15.00. DOI: $10.1086 / 520628$

\section{REFERENCES}

1. Weber SG, Huang SS, Oriola S, et al. Legislative mandates for use of active surveillance cultures to screen for methicillin-resistant Staphylococcus aureus and vancomycin-resistant enterococci: position statement from the Joint SHEA and APIC Task Force. Infect Control Hosp Epidemiol 2007; 28:249-260.

2. Boyce JM, Causey WA. Increasing occurrence of methicillin-resistant Staphylococcus aureus in the United States. Infect Control 1982; 3:377-383.

3. National Statistics. Deaths involving MRSA: England and Wales, 20012005. Health Stat Q 2007;33:76-81.

4. Gould IM. Costs of hospital-acquired methicillin-resistant Staphylococctis aureus (MRSA) and its control. Int J Antimicrob Agents 2006; 28:379-384.

5. Washer P, Joffe $H$. The "hospital superbug": social representations of MRSA. Soc Sci Med 2006; 63:2141-2152.

\section{Occupational Exposures to Bloodborne Pathogens in Smaller Hospitals}

To the Editor-In 2004, the Victorian Hospital Acquired Infection Surveillance System (VICNISS) Coordinating Centre 
TABLE. Rates of Occupational Exposure Involving Acute-Care Inpatients at Smaller Hospitals in Victoria, Australia

\begin{tabular}{lcccc}
\hline & $\begin{array}{c}\text { No. of } \\
\text { No. of } \\
\text { participating } \\
\text { hospitals }\end{array}$ & $\begin{array}{c}\text { accute-care } \\
\text { occupational } \\
\text { exposures }\end{array}$ & $\begin{array}{c}\text { No. of } \\
\text { occupied } \\
\text { bed-days }\end{array}$ & Rate (95\% CI) $^{\text {Exposure type, hospital category }}$ \\
\hline Parenteral occupational exposure & & & & \\
$\quad$ Statewide & 89 & 199 & 568,619 & $3.5(3.0-4.0)$ \\
$\quad$ Small & 54 & 9 & 124,126 & $0.7(0.3-1.4)$ \\
$\quad$ Medium & 24 & 59 & 215,818 & $2.7(2.1-3.5)$ \\
$\quad$ Large & 11 & 131 & 228,675 & $5.7(4.8-6.8)$ \\
Nonparenteral occupational exposure & & & & \\
$\quad$ Statewide & 89 & 52 & 568,619 & $0.9(0.7-1.2)$ \\
$\quad$ Small & 54 & 4 & 124,126 & $0.3(0.1-0.8)$ \\
$\quad$ Medium & 24 & 17 & 215,818 & $0.8(0.5-1.3)$ \\
$\quad$ Large & 11 & 31 & 228,675 & $1.4(0.9-1.9)$ \\
\hline
\end{tabular}

NOTE. A smaller hospital had $<100$ acute-care beds. The group of smaller hospitals was further subdivided into small (1-14 acute-care beds), medium (15-49 acute-care beds), and large (50-99 acute-care beds) hospitals. The table does not include information on 2 exposures that resulted from human bites. $\mathrm{Cl}$, confidence interval.

${ }^{a}$ No. of acute-care occupational exposures per 10,000 acute-care occupied bed-days.

established a surveillance program for smaller hospitals (those with fewer than 100 acute-care beds) located across the state of Victoria, Australia. From January 2005 onward, this program included a module that involved collecting and reporting data on occupational exposures to bloodborne pathogens. This letter reports on the results from the hospitals that participated in this module between January 1, 2005, and June 30, 2006. Most published reports on the epidemiology of occupational exposures are from larger hospitals. ${ }^{1-4}$

Across Victoria, there are now 91 smaller hospitals. These hospitals are further categorized according to the number of acute-care beds-there are 55 small smaller hospitals (with 1-14 acute-care beds), 23 medium smaller hospitals (15-49 acute-care beds), and 13 large smaller hospitals (50-99 acutecare beds). The type and intensity of health care provided vary among these subcategories and are described elsewhere. ${ }^{5}$

Infection control nurses were asked to collect data on all occupational exposures reported by noncasual staff members employed at their hospital during the surveillance period. An occupational exposure was classified as parenteral if the skin or mucous membrane was pierced with a contaminated sharp device or object. These devices and objects included, but were not limited to, needles, scalpels, and broken glass. An occupational exposure was classified as nonparenteral if there was eye, mouth, other mucous membrane, or nonintact skin contact with blood or other potentially infectious materials. A noncasual staff member was defined as someone who had an ongoing expectation of work and was engaged in a regular work roster or pattern of employment.

The number of parenteral and nonparenteral occupational exposures was reported for the following 3 categories of source patients (categorized according tot he type of service in which they were treated): acute-care inpatient, other, and unknown. The rate of occupational exposure to acute-care source patients statewide, as well as at small, medium, and large smaller hospitals, was expressed as the number of parenteral or nonparenteral exposures per 10,000 acute-care occupied bed-days. The occupied bed-days included single-day and multiple-day hospital stays. Emergency department patients were reported as "other" source patients because they were not included in the data on acute-care occupied beddays. The statewide data were also analyzed according to occupational group, the location where the exposure occurred, and the serostatus of the source patient.

For each occupational exposure rate, a corresponding rate at the population level was calculated under the assumption that the occupational exposure count followed a Poisson distribution with a mean proportional to the acute care occupied bed-days; the constant of proportionality in this relationship was the population occupational exposure rate. The effect of hospital size on occupational exposure rates was tested by including it as a 3-category exposure variable in a Poisson regression model for the log (rate) of occupational exposure. All statistical analyses were performed using Stata software, version 9.0 (Stata).

A total of 89 smaller hospitals participated in the occupational exposure module. Aggregate results are presented in the Table. In total, 395 occupational exposures were reported, involving 253 acute-care inpatient source patients, 103 other source patients, and 39 unknown source patients. Two human bites were reported, involving 2 acute-care inpatients. There was strong evidence of a trend of increasing occupational exposure rates with increases in hospital size (ie, the number of acute-care beds) for both parenteral $(P<.001)$ and nonparenteral $(P=.002)$ exposures.

Nurses, the largest segment of the workforce in the Victorian smaller hospitals, were the most commonly affected occupational group (accounting for $59.3 \%$ of exposures), fol- 
lowed by doctors (35.2\%). The majority of occupational exposures occurred in operating rooms $(44.7 \%)$ or inpatient wards $(41.1 \%)$.

Of the 356 source patients categorized as "acute-care inpatient" and "other," 42 had a reported serostatus of either "refused testing" (9.5\%) or "unknown" (90.5\%). Of the 314 remaining source patients in this group, $1(0.3 \%)$ tested positive for hepatitis B surface antigen, and $9(2.9 \%)$ tested positive for hepatitis $C$ virus antibody. No source patients were reported to have tested positive for human immunodeficiency virus antibody.

The VICNISS occupational exposure surveillance module highlighted some useful information about the epidemiology of occupational exposures in the smaller Victorian hospitals. The majority $(97.8 \%)$ of eligible hospitals participated in the module over 19 months. During this period, there were 3.5 parenteral and 0.9 nonparenteral occupational exposures (from an acute-care inpatient source patient) per 10,000 occupied bed-days. Crude comparisons made with another Australian state's aggregate occupational exposure rates suggested that the Victorian aggregate parenteral occupational exposure rate was relatively high. In 2003, New South Wales Group 2 hospitals (described as district hospitals and acutecare and nonacute-care community hospitals) reported 2.7 parenteral occupational exposures per 10,000 patient-days, and in 2004, they reported 2.5 parenteral occupational exposures per 10,000 patient-days. ${ }^{6}$ As in a multihospital study from the United States, the exposure rates were significantly higher in the larger hospitals than in the smaller hospitals. ${ }^{1}$ This is possibly because in smaller hospitals, there are fewer risks per patient for sustaining an occupational exposure (eg, fewer sharp devices are used). ${ }^{7}$ The Victorian results in regard to occupational group, location where the exposure occurred, and serostatus of the source individual were consistent with the literature. . $^{1,8,8}$,

This report has 2 important limitations. First, it did not assess the frequency of underreporting (or any reasons given for underreporting) of occupational exposures by healthcare staff. The literature highlights the fact that underreporting of occupational exposures is common. ${ }^{3,9}$ Second, some denominators used to calculate occupational exposure rates are more meaningful than others. ${ }^{7}$ For example, interpretation of the occupational group data could have been strengthened by obtaining the number of persons in each occupational category (ie, the denominator). This would have enabled the calculation of specific rates for occupational groups, rather than percentages from reported occupational exposures, and it is likely, for example, that the relatively low number of doctors employed would have had significantly higher occupational exposure rates.

To improve the usefulness of the occupational exposure surveillance module, in the future the core data set will include questions about potential precipitating factors. For example, what device or item caused the occupational exposure, and when and how did the occupational exposure occur? Reports will continue to be forwarded to the infection control nurses at participating hospitals, outlining their hospital's results and the aggregate results. It is assumed that, as has been reported elsewhere,$^{10}$ these comparative reports act as an incentive to implement appropriate intervention strategies.

\section{ACKNOWLEDGMENTS}

Potential conflicts of interest. All authors report no conflicts of interest relevant to this article.

Noleen J. Bennett, RN, MPH;

Ann L. Bull, BSc (Hons), MApEpid, PhD;

David R. Dunt, MB, BS, PhD, FFPH; Lyle C. Gurrin, BSc (Hons), PhD; Philip L. Russo, RN, MCE;

Denis W. Spelman, MB, BS, FRACP, FRCPA, MPH; Michael J. Richards, MB, BS, FRACP, MD

From the Victorian Hospital Acquired Infection Surveillance System (VICNISS) Coordinating Centre (N.J.B., A.L.B., P.L.R., M.J.R.), the School of Population Health, University of Melbourne (D.R.D., L.C.G.), and the Microbiology and Infectious Diseases Unit, Alfred Hospital (D.W.S.), Melbourne, Australia.

Address reprint requests to Noleen Bennett, Senior Infection Control consultant, Victorian Hospital Acquired Infection Surveillance System Coordinating Centre, 10 Wreckyn St., North Melbourne 3061, VIC Australia (Noleen.Bennett@mh.org.au).

Infect Control Hosp Epiderniol 2007; 28:896-898

(C) 2007 by The Society for Healthcare Epidemiology of America. All rights reserved. 0899-823X/2007/2807-0025\$15.00. DOI: 10.1086/520628

\section{REFERENCES}

1. Babcock HM, Fraser V. Differences in percutaneous injury patterns in a multi-hospital system. Infect Control Hosp Epidemiol 2003; 24:731-736.

2. Panlilio AL, Orelien JG, Srivastava PU, et al. Data sharing network estimate of the annual number of percutaneous injuries among hospital based healthcare workers in the United States, 1997-1998. Infect Control Hosp Epidemiol 2004; 25:556-562.

3. Doebbeling BN, Vaughn TE, McCoy KD, et al. Percutaneous injury, blood exposure, and adherence to standard precautions: are hospitalbased health care providers at risk? Clin Infect Dis 2003; 37:1006-1013.

4. Smith DR, Leggat PA, Takahashi K. Percutaneous exposure incidents among Australian hospital staff. Int J Occup Saf Ergon 2005; 1:323-330.

5. Bennett NJ, Bull AL, Dunt DR, et al. A profile of smaller hospitals: planning for a novel, statewide surveillance program, Victoria, Australia. Am J Infect Control 2006; 34:170-175.

6. New South Wales (NSW) Health. NSW Infection Rates Report. Infection Control, NSW; 2004. Available at: http://www.health.nsw.gov.au/ health_pr/infection/pdf/occupationalexposurebloodbodyfluid.pdf.

7. Jagger J. Using denominators to calculate percutaneous injury rates. $A d v$ Expos Prev 2002; 6:7-8.

8. Gillen M, McNary J, Lewis J, et al. Sharps related injuries in California healthcare facilities: pilot study results from the sharps injury surveillance registry. Infect Control Hosp Epidemiol 2003; 24:113-121.

9. Jacobsen IT, Burke JP, Conti MT. Injuries of hospital employees from needles and sharp objects. Infect Control 1983; 4:100-102.

10. Gaynes R, Richards C, Edwards J, et al. Feeding back surveillance data to prevent hospital acquired infections. Emerg Infect Dis 2001; 7:295-298. 